\title{
The cost-effectiveness of a family meetings intervention to prevent depression and anxiety in family caregivers of patients with dementia: a randomized trial
}

Karlijn J Joling ${ }^{1 *}$, Judith E Bosmans ${ }^{2}$, Harm WJ van Marwijk ${ }^{1}$, Henriëtte E van der Horst ${ }^{1}$, Philip Scheltens ${ }^{3}$, Janet $L$ MacNeil Vroomen ${ }^{1,4}$ and Hein PJ van Hout ${ }^{1}$

\begin{abstract}
Background: Dementia imposes a heavy burden on health and social care systems as well as on family caregivers who provide a substantial portion of the care. Interventions that effectively support caregivers may prevent or delay patient institutionalization and hence be cost-effective. However, evidence about the cost-effectiveness of such interventions is scarce. The aim of this study was to evaluate the cost-effectiveness of a family meetings intervention for family caregivers of dementia patients in comparison with usual care over a period of 12 months.
\end{abstract}

Methods: The economic evaluation was conducted from a societal perspective alongside a randomized trial of 192 primary caregivers with community-dwelling dementia patients. Outcome measures included the Quality Adjusted Life-Years (QALY) of caregivers and patients and the incidence of depression and anxiety disorders in caregivers. Missing cost and effect data were imputed using multiple imputations. Bootstrapping was used to estimate uncertainty around the cost-differences and the incremental cost-effectiveness ratio (ICER). The bootstrapped cost-effect pairs were plotted on a cost-effectiveness plane and used to estimate cost-effectiveness curves.

Results: No significant differences in costs and effects between the groups were found. At 12 months, total costs per patient and primary caregiver dyad were substantial: $€ 77,832$ for the intervention group and $€ 75,201$ for the usual care group (adjusted mean difference per dyad $€ 4,149,95 \% \mathrm{Cl}-13,371$ to 21,956 , ICER 157,534). The main cost driver was informal care ( $66 \%$ of total costs), followed by patients' day treatment and costs of hospital and long-term care facility admissions (23\%). Based on the cost-effectiveness acceptability curves, the maximum probability that the intervention was considered cost-effective in comparison with usual care reached 0.4 for the outcome QALY per patient-caregiver dyad and 0.6 for the caregivers' incidence of depression and/or anxiety disorders regardless of the willingness to pay.

Conclusions: The annual costs of caring for a person with dementia were substantial with informal care being by far the largest contributor to the total societal costs. Based on this study, family meetings cannot be considered a cost-effective intervention strategy in comparison with usual care.

Trial registration: ISRCTN register, ISRCTN90163486

Keywords: Caregivers, Cost-effectiveness, Dementia, Family meetings, Informal care

\footnotetext{
*Correspondence: k.joling@vumc.nl

${ }^{1}$ Department of General Practice and Elderly Care Medicine, VU University Medical Centre, EMGO + Institute for Health and Health Care Research, Van der Boechorststraat 7, 1081, BT Amsterdam, The Netherlands

Full list of author information is available at the end of the article
} 


\section{Background}

Dementia is a common and disabling disorder in elderly people and the number of people affected is expected to rise exponentially [1]. The majority of people with dementia live in the community where informal caregivers are the main providers of care. Providing care for a relative with dementia can be stressful and demanding, leading to a high burden and significant physical and mental health problems [2-7] compared to non-caregivers [8]. The worldwide costs of dementia (US\$604 billion in 2010) already amount to more than $1 \%$ of the global gross domestic product [9]. Further, dementia patients have increased healthcare utilization rates compared with other major diseases [10-12]. Previous research showed that informal care costs make up a substantial part of the total annual costs of dementia. In the United States, the care provided by informal caregivers to people with dementia was valued at more than $\$ 202$ billion in 2010 [13]. Also, in the United Kingdom and Scandinavia, informal care account for a substantial proportion $(55 \%$ and $33 \%$, respectively) of the annual cost of dementia [14,15]. In several countries, the current health care workforce may not be numerous enough to meet the care needs of the increasing number of older patients; this might place even more pressure on family and other informal caregivers in the near future [16-19].

Dementia thus imposes a heavy economic burden on the social care system, as well as on family and friends who provide unpaid care. Interventions which effectively support caregivers and prevent psychiatric morbidity may postpone institutionalization of the patient with dementia $[20,21]$, decrease work absenteeism and healthcare utilization of the caregiver and may hence be cost-effective in comparison with usual care. Information about the tradeoff between costs and benefits of caregiver interventions is urgently needed since it will enable policy makers to understand the magnitude of the economic consequences and to decide whether it is efficient to implement such interventions considering the scarce resources available for healthcare. A large number of studies evaluated the effectiveness of supportive interventions for informal caregivers of people with dementia [22-24], but recent reviews showed that there are only few economic evaluations of such interventions. Moreover, the available studies in this field often have insufficient methodological quality and measured costs from a narrow perspective $[25,26]$. Some studies analysed effect and cost differences between groups separately instead of comparing the total cost of each option against the total effects. Furthermore, often not all relevant cost categories such as informal care costs and lost productivity costs were taken into consideration, and hence, these studies were not performed from a societal perspective. The systematic review of Jones et al. [25] on the costeffectiveness of interventions targeted at informal dementia caregivers identified only four psychosocial interventions and four other types of non-pharmacological interventions that were evaluated in studies with sufficient quality [25]. Only one of these psychosocial interventions reported to be cost-effective compared with usual care [27].

A psychosocial intervention targeted at the whole family, such as family meetings, may be a potentially costeffective approach. Family meetings may maximize the positive contribution of family members, decrease caregiver burden, alleviate psychological symptoms [28,29] or even prevent the primary caregiver from developing a psychiatric disorder, such as a depressive or anxiety disorder. This might enable the caregiver to provide care for a longer time, thereby leading to decreased healthcare utilization and loss of productivity and postponement of patient institutionalization. Previously, a multi-component intervention program for caregivers that consisted of four family meetings, two individual counselling sessions with the caregiver, support group participation and ad hoc counselling was shown to decrease depressive symptoms in informal caregivers and to result in a substantial delay in time until nursing home placement of patients [20,21,28-30]. Joling et al. subsequently investigated, in a pragmatic trial, whether a structured family meetings intervention could prevent mental disorders and reduce the severity of symptoms in caregivers of persons with dementia thus delaying institutionalization of patients. Clinically, the effects were smaller than anticipated. Although the incidence of depression and anxiety disorders was substantial in the sample of caregivers, the intervention did not prevent the onset of disorders, nor reduce symptom levels or delayed time until institutionalization of patients compared to usual care [31-33]. Evidence on the cost-effectiveness of family meetings is still lacking; little is known about the costs associated with such interventions and the relationship between costs and effects. This article presents the first cost-effectiveness analysis alongside a randomized trial of a family meeting intervention for caregivers of patients with dementia in comparison with usual care.

\section{Methods}

\section{Study design, setting and participants}

The economic evaluation was performed alongside a randomized trial to evaluate a family meetings intervention in comparison with usual care from a societal perspective. The follow-up of the study was 12 months. Caregiver and patient dyads were recruited through memory clinics $(\mathrm{n}=$ $91)$, organizations delivering case management $(n=79)$, general practices, home care settings and meeting centres for people with dementia and their caregivers $(n=22)$ in the Netherlands. Caregivers were eligible if they were the primary family caregiver of a community-dwelling relative with a clinical diagnosis of dementia and had at least one other family member or friend available to participate in 
the family meetings. If there was more than one family caregiver caring for the patient, the primary caregiver was defined as the person who coordinated the caring process, usually the person who spent most hours on caregiving tasks. Caregivers were excluded when 1) they met the criteria for a clinical depressive or anxiety disorder as measured with the Mini International Neuropsychiatric Interview (MINI) [34], 2) their relative with dementia was scheduled to move into a nursing home, 3) they presented with severe somatic or psychiatric co-morbidity which would significantly impair cooperation with the study. Persons who gave written informed consent and had sufficient command of the Dutch language were eligible for participation in the study; the design of the study has been described in detail elsewhere [31]. The Medical Ethics Committee of the VU University Medical Centre approved the study protocol.

\section{Randomization and blinding}

After obtaining signed informed consent and baseline measurements, dyads of patients and their primary family caregiver were randomized by an independent researcher stratified by recruitment centre in blocks of four to either usual care or the family meetings intervention. The interviewers who measured the outcomes were blinded to randomization status. Blinding of participants and the counsellors conducting the family meetings was not possible due to the nature of the intervention.

\section{Intervention}

The family meetings intervention has been described in detail elsewhere [31,32]. Briefly, caregivers randomized to the intervention group were invited to participate in six in-person counselling sessions: one individual preparation session, followed by four structured meetings that included their relatives and/or friends (family meetings), and one additional individual evaluation session. The family meetings were held once every 2 to 3 months in the year following enrolment in the program. The aim of the family meetings was to offer psycho-education, teach problemsolving techniques and mobilize the existing family networks of the patient and primary caregiver in order to improve emotional and instrumental support. The content of the sessions was guided by the needs of the caregiver. The intervention protocol recommended that patients would not attend the family meetings, unless the caregiver strongly desired the patient to be present. Ad hoc telephone counselling from the same counsellor was available to caregivers and their families beyond the scheduled sessions. The counsellors who led the family meetings had an advanced degree in nursing, social work, psychology or an allied profession and were trained prior to the study by the research team. The total estimated time for the intervention was 6.5 hours per patient-caregiver dyad, including the time spent for the individual and family sessions (5.5 hours) and administration and preparation time for the counsellor (1 hour). Intervention participants also had access to all the usual types of care.

\section{Usual care}

Participants randomized to the usual care group were free to use all types of care, including community-based mental health services or support resources other than family meetings at any time throughout the 12 months follow-up, reflecting standard care. Usual care in the Netherlands may consist of a range of health and social care services and can differ across participants. However, family meetings are rarely organized or offered in a structured way with follow-up sessions. They also tend to focus on providing clinical information and not on increasing family support and relieving the caregiver.

\section{Effect outcomes}

Effect outcomes were the quality of life of the patient and caregiver (as a dyad and separately) and the incidence of major depressive or anxiety disorders in caregivers. Qualityof-life of caregivers and patients was measured using the SF-12 at baseline and at 6 and 12 months [35]; the caregiver rated the patient's quality of life. The tariff developed by Brazier et al. [36] was used to convert health states to utilities [36]. Utilities express the relative desirability of a health state on a scale of 0 ('death') to 1 ('perfect health'). QALYs were calculated by multiplying the utilities with the amount of time a person spent in a particular health state. Transitions between health states were linearly interpolated.

The incidence of depression and anxiety was measured at baseline and at 3, 6, 9 and 12 months after enrolment with the MINI [34], a short diagnostic interview for DSM-IV mental disorders that can be used for psychiatric evaluation and outcome tracking.

\section{Cost outcomes}

Cost data were collected from a societal perspective using two consecutive cost diaries that covered a period of 6 months each as well as 6-monthly interview assessments to measure informal care time; direct and indirect costs of both the caregiver and patient were gathered. Table 1 lists the cost categories and prices used in this economic evaluation. All costs were adjusted to the year 2009 using consumer price indices if necessary. The year 2009 was chosen because most cost data were collected during that year. Costs were calculated by multiplying the units of resource use by their cost price according to the Dutch guidelines for health economic evaluations [37]. If no standard cost was available, tariffs were used. Medication costs were valued using prices of the Royal Dutch Society for Pharmacy [38]. Lost productivity costs were calculated according to the friction cost approach 
Table 1 Prices used in the economic evaluation and utilization of health care resources and work absenteeism for caregivers and patients with complete cost data during the 12-month follow-up period

\begin{tabular}{|c|c|c|c|c|}
\hline Cost category & Unit & $\begin{array}{l}\text { Unit cost } \\
(€, 2009)\end{array}$ & $\begin{array}{l}\text { Caregivers } \\
(\mathrm{n}=125) \\
\text { Mean (SD) }\end{array}$ & $\begin{array}{l}\text { Patients } \\
(n=118) \\
\text { Mean (SD) }\end{array}$ \\
\hline \multicolumn{5}{|l|}{ Ambulatory care (except home care) } \\
\hline General practitioner & Contact & $28^{\mathrm{a}}$ & $5.0(4.3)$ & $4.9(5.4)$ \\
\hline Paramedical therapist & Contact & Variable ${ }^{b}$ & $7.3(14.3)$ & $10.2(19.9)$ \\
\hline Psychologist or psychotherapist & Contact & 80 or 77 & $0.5(2.7)$ & $0.2(0.7)$ \\
\hline Social worker & Contact & 65 & $0.2(1.0)$ & $0.4(2.0)$ \\
\hline Social psychiatric nurse & Contact & 45 & $1.7(3.3)$ & $1.8(3.6)$ \\
\hline Psychiatrist & Contact & 171 & $0.03(0.4)$ & $0.2(0.7)$ \\
\hline Other counsellor ${ }^{c}$ & Contact & Variable & $0.3(1.5)$ & $\mathrm{n} / \mathrm{a}$ \\
\hline Peer support group counselling & Session & 68 & $1.8(3.8)$ & $0.1(0.7)$ \\
\hline Outpatient appointment & Contact & 72 & $2.6(3.0)$ & $3.9(3.8)$ \\
\hline \multicolumn{5}{|l|}{ Home care and other support } \\
\hline Domestic home help & Hour & 24 & $10.6(17.5)$ & see caregiver \\
\hline Professional home care & Hour & 44 & $0.5(4.2)$ & $5.4(15.8)$ \\
\hline Respite care & Hour & 12.50 & $1.6(8.3)$ & $n / a$ \\
\hline Meal supply at home & Meal & 6 & $2.7(20.6)$ & $3.4(22.8)$ \\
\hline \multicolumn{5}{|l|}{ Day treatment and admissions } \\
\hline Day treatment & Day & 251 & $1.6(8.2)$ & $48.3(67.2)$ \\
\hline Admission, elderly home & Day & 90 & $0.2(2.3)$ & $1.1(7.6)$ \\
\hline Admission, nursing home & Day & 238 & $0.4(3.8)$ & $15.2(46.1)$ \\
\hline Admission, academic hospital & Day & 575 & $0.2(2.0)$ & $0.3(1.8)$ \\
\hline Admission, non-academic hospital & Day & 435 & $0.4(1.9)$ & $1.0(5.5)$ \\
\hline Admission, intensive care unit & Day & 2183 & $0.02(0.2)$ & none \\
\hline \multicolumn{5}{|l|}{ Absenteeism } \\
\hline Paid labour & Day & Friction costs ${ }^{d}$ & $2.2(11.7)$ & $\mathrm{n} / \mathrm{a}$ \\
\hline Unpaid labour & Hour & 12.50 & $4.7(20.7)$ & $\mathrm{n} / \mathrm{a}$ \\
\hline Informal care & Hour & 12.50 & see patient & $3760.3(3273.0)$ \\
\hline
\end{tabular}

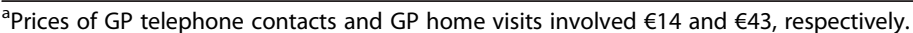

${ }^{\mathrm{b}}$ Paramedical therapists included: physiotherapist, manual therapist, Cesar exercise therapists, alternative therapists. For each profession, the appropriate guideline price was used and if not available, the mean of the price according to five therapists was used.

'Other counsellors included counselling sessions with a caregiver consultant, a coordinator of meeting centres for persons with dementia and their caregivers or a practice nurse. Prices were according to the professional organization.

${ }^{d}$ Costs for paid labour were calculated on the basis of a mean income of the Dutch population according to age and sex.

(friction period 154 days) using the mean age and sex specific income of the Dutch population [39,40]. The intervention costs were calculated based on the time investment of the counsellors including 15 minutes of administration by the counsellors per family session and the time spent by the counsellors on the individual and family counselling sessions ( $€ 45.35$ per hour). Travel costs and capital costs were not included. Informal caregiver time was valued using a shadow price based on the hourly cost of a legally employed cleaning person ( $€ 12.50$ per hour) as recommended in the Dutch guidelines. Caregivers were asked how much time they spent on a list of informal care tasks during the previous day. Informal care tasks included: support with activities of daily living (ADL), support with instrumental activities of daily living (IADL), household activities of daily living (HDL) and supervision tasks. The total informal care time was calculated by adding up the reported time on these tasks during the previous day, using a maximum of 24 hours. We extrapolated the time per day reported at baseline, 6 and 12 months to determine the total amount of carer time during 12 months of follow-up.

\section{Power calculation}

The power calculation was based on the expected effects of the intervention on the main outcome measure, incidence of a depression or anxiety disorder. The yearly incidence of disorders among caregivers at risk was estimated at $30 \%$ [3]. The trial was powered to detect a $20 \%$ decrease 
in the incidence. We calculated that 73 participants per group would be needed, assuming a 2-sided test, an alpha of 0.05 and a power of $80 \%$. With a dropout of $20 \%$, at least 182 participants were needed.

\section{Statistical analysis}

The economic evaluation included a cost-utility analysis with the QALY as the effect (analysed for the patientcaregiver dyad as well as for caregivers and patients QALYs separately) and a cost-effectiveness analysis with the caregiver's incident depression and/or anxiety disorder as the effect. The statistical analyses were performed according to the intention-to-treat principle (ITT). Multiple imputation was used to impute missing cost and effect data. Variables found to be related to cost and effect outcomes and missing follow-up data, were included in the multiple imputation model. Each of the 10 imputed data sets were separately analysed and the results of the 10 analyses were pooled using Rubin's rules [41]. To adjust for selection bias, variables with significant baseline differences between the intervention and usual care group (caregiver anxiety score (HADS-A) [42], age of the patient and age of the caregiver) were incorporated as covariates in the analyses. For costs, linear regression models were estimated. Costs generally have a highly skewed distribution; therefore, bootstrapping with 5,000 replications was used to estimate bias-corrected and accelerated confidence intervals around cost differences $[43,44]$. Cost-effectiveness was expressed as an incremental cost effectiveness ratio (ICER) for the intervention compared to the control condition, a measure of the additional cost per unit of health gain. ICERs were calculated by dividing the difference in total costs between the intervention and usual care group by the difference in clinical effects. A bivariate regression model was estimated with separate regression equations for costs and effects including covariates. Non-parametric bootstrapping was also used to estimate the uncertainty surrounding the incremental cost-effectiveness and cost-utility ratios (5,000 replications). The bootstrapped cost-effect pairs were plotted on a costeffectiveness plane and used to estimate cost-effectiveness acceptability (CEA) curves. In a cost-effectiveness plane, incremental costs between the intervention and usual care are plotted on the $y$-axis and incremental effects on the $x$ axis resulting in four quadrants. The northeast quadrant indicates that the intervention is more expensive and more effective than usual care. In the southeast quadrant the intervention dominates usual care, i.e. is less expensive and more effective than usual care. In the southwest quadrant the intervention is less expensive and less effective than usual care. Finally, in the northwest quadrant the intervention is dominated by usual care (more expensive and less effective). Most newly developed interventions are more expensive and more effective than usual care, which implies that a trade-off needs to be made about whether the additional benefits justify the additional costs. This decision depends on the societal willingness to pay for an additional unit of effect. However, this willingness to pay is generally not known. CEA curves show the probability that the intervention is cost-effective in comparison with the control treatment for a range of willingness to pay values [45]. Finally, two sensitivity analyses were carried out. Complete case analyses were performed using only persons with complete follow-up cost and effect data to assess whether missing data might have caused bias. Furthermore, the ITT analyses were repeated without adjustment to assess the impact of the baseline imbalances and to check the robustness of the results.

\section{Results}

\section{Participant flow and recruitment}

Participants were recruited from November 2007 to November 2009. Figure 1 presents the flow chart of the study sample. Of the caregivers assessed for eligibility, 192 met all inclusion criteria and were willing to participate. Reasons for exclusion included not meeting the inclusion criteria $(\mathrm{n}=81)$ and refusal of participation $(\mathrm{n}=$ 410) and were described in detail elsewhere [32]. Summarized, the primary reason for refusal was a claimed lack of need for this intervention. There were no significant differences between the patient-caregiver dyads that refused participation and the participating dyads in gender, caregiver-patient relation and the type of service they were recruited from.

\section{Baseline characteristics}

Table 2 presents the socio-demographic and clinical characteristics of the caregivers and patients at baseline. Patients and caregivers in the intervention group were significantly younger (patient's age: $t=3.07$, degrees of freedom $(\mathrm{df})=$ 188.10, 95\% CI for difference in means: 1.37 to 6.33, and caregivers' age: $\mathrm{t}=2.27, \mathrm{df}=188.47,95 \%$ CI: 0.45 to 6.30 ) and caregivers in the intervention group had higher levels of anxious symptoms (HADS-A score) $(\mathrm{t}=-2.51, \mathrm{df}=187$, 95\% CI for difference in means: -2.22 to -0.27 ) at baseline than participants in the usual care group.

\section{Numbers analysed}

Complete follow-up data (cost data and both the QALY and MINI effect outcome data) were available for 44 (46\%) intervention and 57 (59\%) usual care group caregivers. For patients, complete follow-up data were available for $48 \mathrm{pa}$ tients $(50 \%)$ in the intervention group and 54 patients (56\%) in the usual care group. Missing follow-up data was significantly associated with the number of ADL dependencies (mean difference $0.44,95 \%$ CI 0.09 to 0.79 ), the number of IADL dependencies (mean difference 0.75, 95\% CI 0.29 to 1.21 ) and lower mini mental state examination scores (mean difference $-1.92,95 \% \mathrm{CI}-3.46$ to -0.37 ) of 


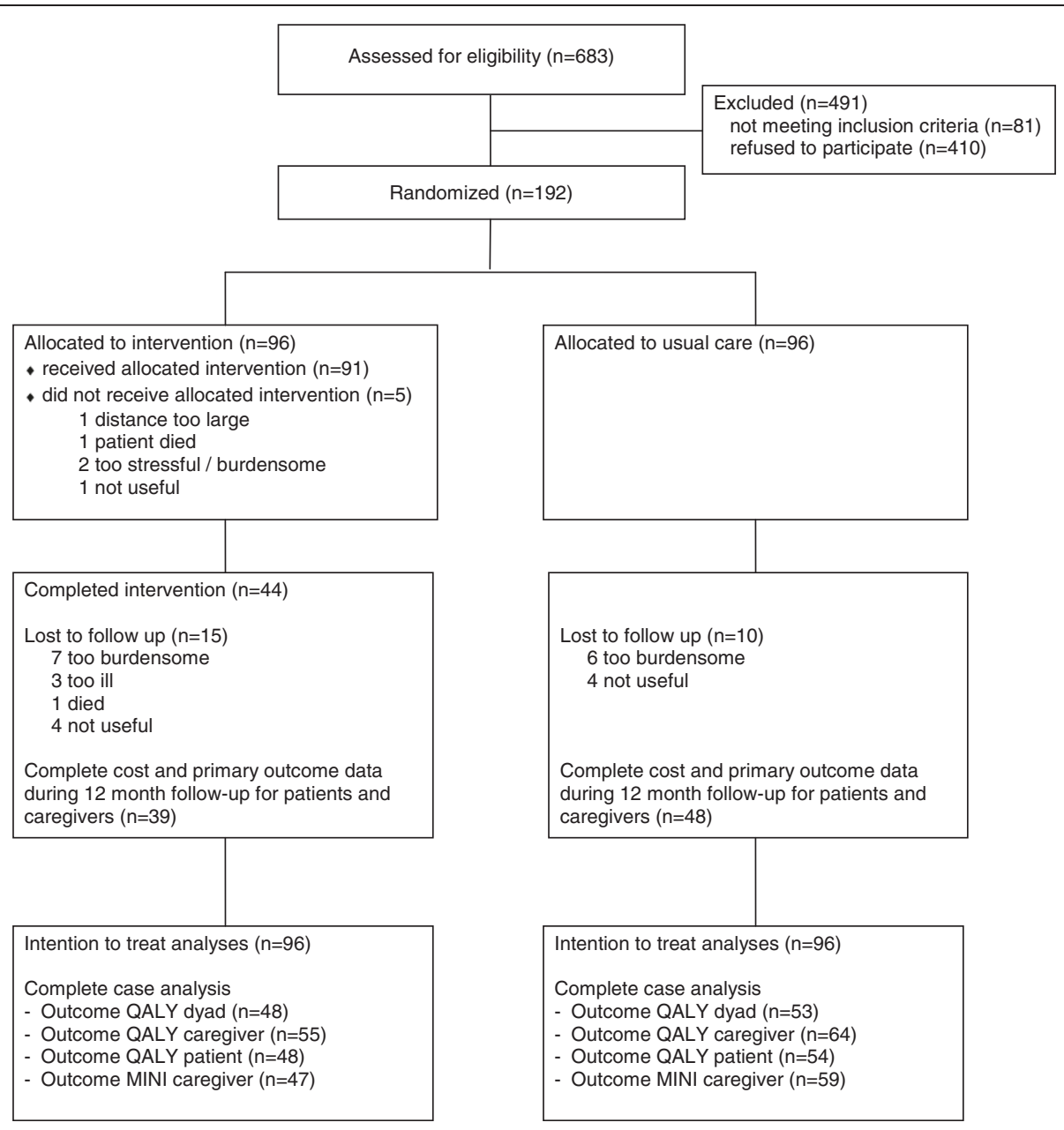

Figure 1 Flow chart of the study sample.

Table 2 Baseline demographic and clinical characteristics of the caregivers and patients

\begin{tabular}{|c|c|c|c|c|}
\hline & \multicolumn{2}{|c|}{ Caregiver } & \multicolumn{2}{|c|}{ Patient } \\
\hline & Intervention $(n=96)$ & Usual care $(n=96)$ & Intervention $(n=96)$ & Usual care $(n=96)$ \\
\hline Age, M (SD) & $67.8(9.8)^{*}$ & $71.2(10.7)$ & $72.8(9.1)^{*}$ & $76.7(8.3)$ \\
\hline Female gender, $\mathrm{n}(\%)$ & $67(69.8)$ & $68(70.8)$ & $30(31.3)$ & $32(33.3)$ \\
\hline Spouse of the patient, n (\%) & $92(95.8)$ & $89(92.7)$ & & \\
\hline Living with patient, $\mathrm{n}(\%)$ & $93(96.9)$ & $91(94.8)$ & & \\
\hline \multicolumn{5}{|l|}{ Educational level, n (\%) } \\
\hline Elementary/Lower & $28(29.2)$ & $34(35.4)$ & $42(43.8)$ & $44(45.8)$ \\
\hline Secondary & $37(38.5)$ & $30(31.3)$ & $30(31.3)$ & $28(29.2)$ \\
\hline Higher/ University & $29(30.2)$ & $32(33.3)$ & $24(25.0)$ & $22(22.9)$ \\
\hline Utility score SF6D, M (SD) & $0.8(0.01)$ & $0.7(0.01)$ & $0.7(0.01)$ & $0.7(0.01)$ \\
\hline Anxiety score HADS-A (0-21), M (SD) & $6.1(3.4)^{*}$ & $4.8(3.5)$ & & \\
\hline Depression score CES-D (0-60), M (SD) & $12.1(7.9)$ & $10.8(7.1)$ & & \\
\hline ADL independencies (out of 6), M (SD) & & & $5.1(1.4)$ & $5.3(1.1)$ \\
\hline IADL independencies (out of 7), M (SD) & & & $2.7(1.8)$ & $2.6(1.5)$ \\
\hline MMSE (0-30), M (SD) & & & $21.4(4.9)$ & $21.7(5.6)$ \\
\hline
\end{tabular}

M: Mean; SD: Standard deviation; HADS-A: Hospital Anxiety and Depression Scales- Anxiety subscale; CES-D: Centre for Epidemiologic Studies Depression Scale; (I) ADL: (Instrumental) activities of daily living; MMSE: Mini Mental State Examination.

*significant difference with usual care group $(P<0.05)$. 
patients at baseline. In accordance with the ITT principle, missing follow-up data were imputed and all participants were included in the analyses.

\section{Uptake of the intervention}

Of those randomized to the intervention group, 91/96 participated in the preparation session, 73/96 attended 1 or 2 family meetings and 44/96 adhered (i.e., completed the preparation session plus 3 or 4 family meetings within 12 months) to the intervention protocol.

\section{Costs}

Table 3 presents the mean costs and adjusted differences in costs for caregivers and patients between the intervention and usual care group. Ambulatory care costs in the intervention group were significantly lower. Further, considerable investments need to be done to provide the intervention in addition to usual care. Total costs were $€ 77,832$ per patient-caregiver dyad in the intervention group and $€ 75,201$ in the usual care group (mean adjusted difference $€ 4,149,95 \%$ CI $-13371 ; 21956)$. Patient costs were the majority of the total costs $(€ 73,854$ in the intervention group and $€ 70,684$ in the control group per patient) and only a relatively small amount concerned costs for caregivers $(€ 3,979$ in the intervention group and $€ 4,517$ in the control group per caregiver). Although statistically non-significant, costs for caregivers were in favour of the intervention group (mean adjusted difference $€ 788,95 \%$ CI -3529 ; 1439), while for patients costs were lower in the usual care group (mean adjusted difference $€ 4,936,95 \%$ CI -11808 ; 21750), which was mainly due to lower informal care costs. Informal care costs were by far the largest contributor to total dyadic costs (66\%) with an average amount of $€ 50,859$. This means that caregivers spent on average 11 hours per day on caregiving, including supervision. Another large cost driver involved day treatment and admissions of the patient to hospitals and long-term care facilities which amounted to an average of $€ 17,756$ per patient. The volumes of resource use for patients and caregivers with complete cost data are shown in Table 1.

\section{Effects}

Full details on the clinical outcomes were presented in the accompanying clinical paper [32,33]. Briefly, a substantial number $(37 / 96 ; 39.6 \%)$ of caregivers in the intervention group and in the usual care group (34/96; 35.4\%) developed a depressive or anxiety disorder within 12 months. The incidence was similar in both groups (adjusted difference 0.01 ; $95 \%$ CI -0.14 to 0.17 , Table 4). There was no statistically significant difference in quality of life for either the patients, caregivers or patient-caregiver dyads (Table 4).

\section{Cost-effectiveness}

Since the differences in effects on all outcomes were very small, this resulted in very large ICERs that will be very sensitive to uncertainty in incremental effect (Table 4). Figure 2 shows that most cost-effect pairs for the

Table 3 Unadjusted and adjusted differences in costs $(€)$ for caregivers and patients after 12 months of follow-up

\begin{tabular}{|c|c|c|c|c|c|c|}
\hline \multirow[t]{2}{*}{ Cost category } & \multirow{2}{*}{$\begin{array}{r}\text { Intervention }(\mathrm{n}=96) \\
M(\mathrm{SD})\end{array}$} & \multirow{2}{*}{$\begin{array}{r}\text { Usual care }(n=96) \\
M(S D)\end{array}$} & \multirow{2}{*}{$\begin{array}{r}\text { Unadjusted } \\
\text { difference }\end{array}$} & \multirow[t]{2}{*}{$95 \% \mathrm{Cl}^{*}$} & \multirow[t]{2}{*}{$\begin{array}{l}\text { Adjusted } \\
\text { difference }^{* *}\end{array}$} & \multirow[t]{2}{*}{$95 \% \mathrm{Cl}$} \\
\hline & & & & & & \\
\hline \multicolumn{7}{|l|}{ Caregiver } \\
\hline Ambulatory care & $842(103)$ & $1,110(124)$ & -268 & $-571 ; 20$ & -335 & $-663 ;-28^{* * *}$ \\
\hline Day treatment and admissions & $854(454)$ & $1,074(436)$ & -220 & $-1371 ; 1081$ & -107 & $-1327 ; 1272$ \\
\hline Home care and other support & $751(171)$ & $1,253(247)$ & -502 & $-1151 ; 7$ & -438 & $-1015 ; 57$ \\
\hline Absenteeism & $1,133(640)$ & $691(458)$ & 442 & $-742 ; 2058$ & 57 & $-1366 ; 1436$ \\
\hline Medication & $271(48)$ & $389(57)$ & -118 & $-266 ; 19$ & -94 & $-259 ; 48$ \\
\hline Intervention & $129(10)$ & 0 & 129 & $110 ; 147^{* * *}$ & 129 & $109 ; 149^{* * *}$ \\
\hline Total caregiver & $3,979(884)$ & $4,517(876)$ & -538 & $-2976 ; 1681$ & -788 & $-3529 ; 1439$ \\
\hline \multicolumn{7}{|l|}{ Patient } \\
\hline Ambulatory care & $1,057(115)$ & $1,016(126)$ & 41 & $-274 ; 328$ & -81 & $-438 ; 221$ \\
\hline Day treatment and admissions & $18,388(2639)$ & $17,124(2735)$ & 1264 & $-6122 ; 8436$ & 1208 & $-6017 ; 8620$ \\
\hline Home care and other support & $1,451(425)$ & $1,581(482)$ & -130 & $-1362 ; 1121$ & -109 & $-1439 ; 1177$ \\
\hline Medication & $1,097(131)$ & $1,106(102)$ & -9 & $-284 ; 308$ & -98 & $-374 ; 182$ \\
\hline Informal care & $51,860(4585)$ & 49,858 (4065) & 2002 & $-10082 ; 13877$ & 4017 & $-8541 ; 16715$ \\
\hline Total patient & $73,854(6106)$ & $70,684(5706)$ & 3170 & $-13398 ; 19776$ & 4936 & $-11808 ; 21750$ \\
\hline Total patient- caregiver dyad & $77,832(6384)$ & $75,201(5997)$ & 2631 & $-14520 ; 20118$ & 4149 & $-13371 ; 21956$ \\
\hline
\end{tabular}

${ }^{*} 95 \% \mathrm{Cl}$ obtained by bias corrected and accelerated bootstrapping.

** Cost differences adjusted for variables that differed significantly between intervention and usual care group at baseline (age caregiver, age patient, HADS anxiety score).

*** Indicates a statistically significant difference between the intervention and usual care group. 
Table 4 Results of the cost-effectiveness analyses for the outcomes MINI and QALYs

\begin{tabular}{|c|c|c|c|c|c|c|c|c|c|c|c|}
\hline \multirow[t]{2}{*}{ Analysis } & \multirow[t]{2}{*}{ Outcome } & \multirow[t]{2}{*}{$\mathrm{N}$} & \multirow[t]{2}{*}{$\Delta$ effects } & \multirow[t]{2}{*}{$95 \% \mathrm{Cl}$} & \multirow[t]{2}{*}{$\Delta$ costs } & \multirow[t]{2}{*}{$95 \% \mathrm{Cl}^{\#}$} & \multirow[t]{2}{*}{ ICER } & \multicolumn{4}{|c|}{$\begin{array}{l}\text { Distribution cost- } \\
\text { effectiveness plane (\%) }\end{array}$} \\
\hline & & & & & & & & NE & SE & SW & NW \\
\hline \multirow[t]{4}{*}{ ITT Unadjusted } & Patient-caregiver dyad QALY & 192 & 0.006 & $-0.05 ; 0.06$ & 2631 & $-14520 ; 201118$ & 438299 & 31 & 27 & 12 & 30 \\
\hline & Caregiver QALY & 192 & 0.004 & $-0.04 ; 0.04$ & -538 & $-2976 ; 1681$ & -149984 & 15 & 43 & 25 & 17 \\
\hline & Patient QALY & 192 & 0.002 & $-0.04 ; 0.04$ & 3169 & $-13398 ; 19776$ & 1313110 & 31 & 25 & 11 & 33 \\
\hline & $\begin{array}{l}\text { Caregiver incidence of depression } \\
\text { and/or anxiety (MINI)* }\end{array}$ & 192 & -0.04 & $-0.20 ; 0.11$ & -538 & $-2976 ; 1681$ & 12604 & 8 & 21 & 47 & 24 \\
\hline \multirow[t]{4}{*}{ ITT Adjusted } & Patient-caregiver dyad QALY & 192 & 0.04 & $-0.03 ; 0.08$ & 4149 & $-13483 ; 21965$ & 157534 & 54 & 30 & 3 & 13 \\
\hline & Caregiver QALY & 192 & 0.02 & $-0.005 ; 0.05$ & -788 & $-3551 ; 1453$ & -32254 & 24 & 71 & 3 & 2 \\
\hline & Patient QALY & 192 & 0.002 & $-0.03 ; 0.04$ & 4936 & $-11631 ; 22073$ & 2574938 & 35 & 19 & 9 & 37 \\
\hline & $\begin{array}{l}\text { Caregiver incidence of depression } \\
\text { and/or anxiety }(\mathrm{MINI})^{*}\end{array}$ & 192 & 0.01 & $-0.14 ; 0.17$ & -788 & $-3566 ; 1399$ & -59011 & 14 & 44 & 31 & 12 \\
\hline \multirow[t]{4}{*}{ CCA } & Patient-caregiver dyad QALY & 101 & -0.005 & $-0.08 ; 0.07$ & 3951 & $-17662 ; 25955$ & -807703 & 23 & 20 & 16 & 40 \\
\hline & Caregiver QALY & 119 & 0.02 & $-0.02 ; 0.05$ & -483 & $-2514 ; 1720$ & -24472 & 25 & 62 & 6 & 8 \\
\hline & Patient QALY & 102 & -0.02 & $-0.07 ; 0.03$ & 4373 & $-16422 ; 25402$ & -240247 & 12 & 12 & 22 & 54 \\
\hline & $\begin{array}{l}\text { Caregiver incidence of depression } \\
\text { and/or anxiety }(\mathrm{MINI})^{*}\end{array}$ & 106 & 0.08 & $-0.06 ; 0.21$ & -711 & $-2783 ; 1775$ & -9271 & 20 & 68 & 9 & 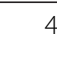 \\
\hline
\end{tabular}

ITT: Intention to treat; CCA: Complete case analysis.

${ }^{\#} 95 \% \mathrm{Cl}$ obtained by bias corrected and accelerated bootstrapping.

*An effect difference $>0$ means that over a period of 12 months the risk of an incident depression and/or anxiety disorder was lower in the intervention group compared to the usual care group.

outcome QALY per care dyad (patient and caregiver combined) were contained in the northeast quadrant of the cost-effectiveness plane indicating some higher effects accompanied by some higher costs of the intervention compared with usual care (non-significant). The cost-effectiveness analysis for the QALY was repeated for patients and caregivers separately, but this revealed no significant differences either (Table 4). Based on the CEA curves, the probability that the intervention was considered cost-effective in comparison with usual care was 0.33 for the outcome QALY per care dyad when the ceiling ratio is set at $€ 0 / \mathrm{QALY}$ and was 0.36 for a ceiling ratio of $€ 30,000 / \mathrm{QALY}$ (Figure 3). For caregivers separately, this probability was 0.73 for a ceiling ratio of $€ 0 /$ QALY and 0.85 for a ceiling ratio of $€ 30,000 / Q A L Y$. For patients, the probability remained around 0.29 for both ceiling ratios of $€ 0 / \mathrm{QALY}$ and $€ 30,000 / \mathrm{Q} A L Y$. For infinite values of willingness to pay, the maximum probabilities were $0.74,0.95$ and 0.54 for the dyads, caregivers and patients, respectively (figures for caregivers and patients separately not shown).

Figure 4 shows the cost-effectiveness plane for the outcome incident depression and/or anxiety, which incorporated the cost and effects for the caregiver only. The

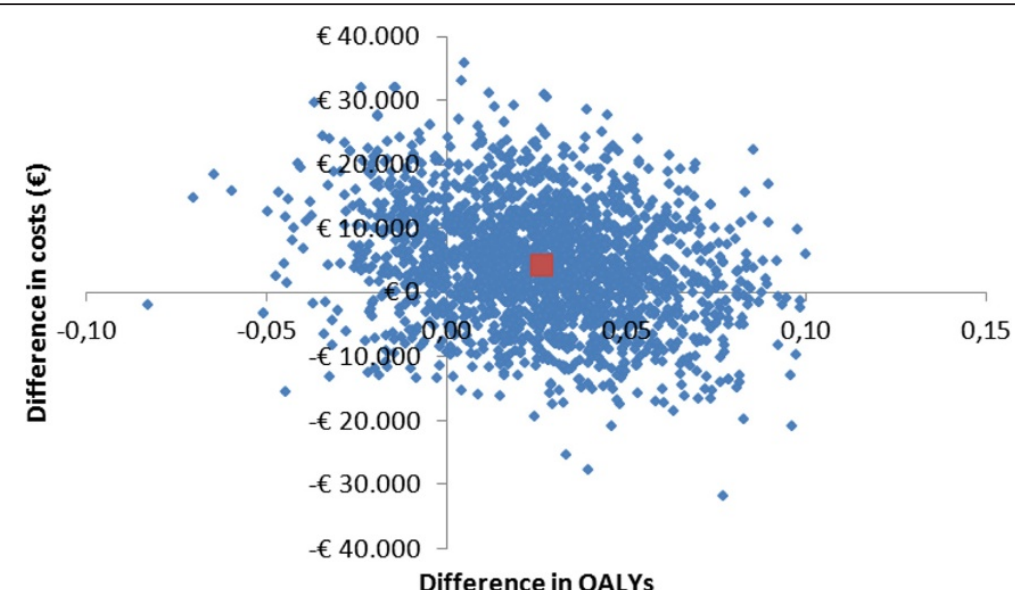

Difference in QALYs

Figure 2 Cost-effectiveness plane for the difference in Quality Adjusted Life-Years (QALYs) per dyad gained at 12 months. 


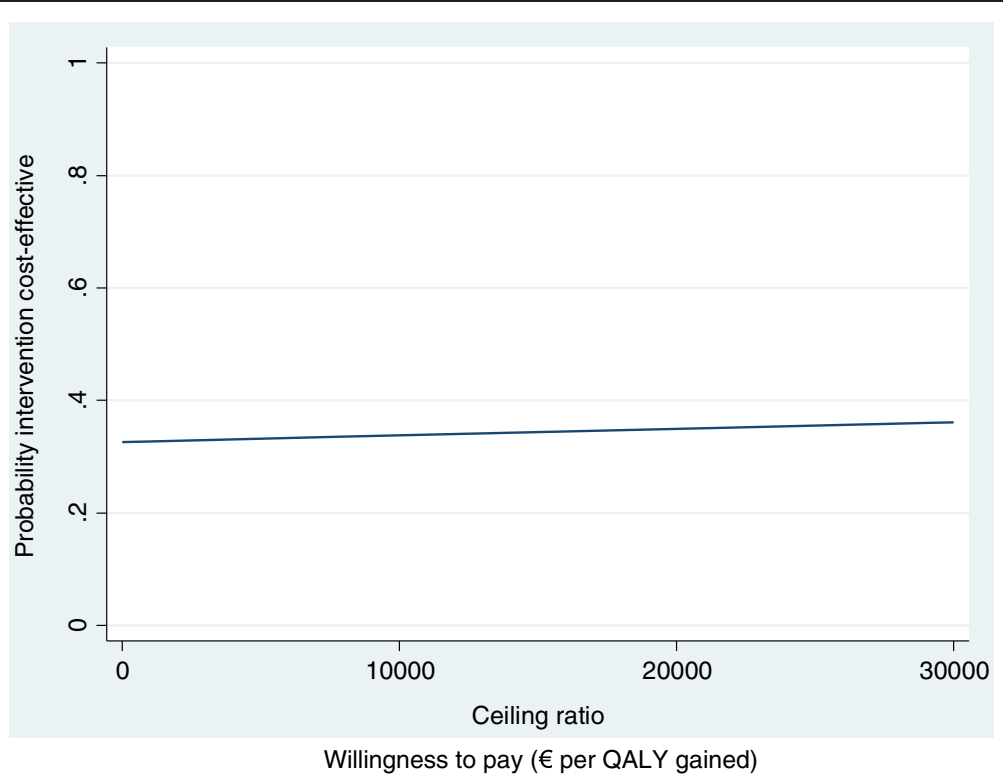

Figure 3 Cost-effectiveness acceptability curve for the outcome Quality Adjusted Life-Years (QALYs) per dyad. Willingness to pay (€ per QALY gained).

majority of the cost-effectiveness pairs $(75 \%)$ were located in the southern quadrants, with a somewhat higher proportion in the Eastern quadrant, suggesting that the intervention has lower costs accompanied by higher effects for caregivers compared with usual care, although these differences were statistically non-significant. The CEA curve for this outcome shows that the maximum probability that the intervention is cost-effective in comparison with usual care was 0.73 at a willingness to pay of zero euros. With increasing values for willingness to pay, the probability that the intervention is cost-effective in comparison with usual care goes towards 0.57. The curve decreases because the cost difference for caregivers is in favour of the intervention group (Figure not shown).

\section{Sensitivity analyses}

Two sensitivity analyses were carried out. The first involved a complete case analysis using only persons with complete follow-up data. For complete cases, the intervention was not considered cost-effective in comparison with usual care on any of the outcome measures. Effect differences for all outcomes remained small and non-significant (Table 4). The total costs per care dyad (patient and caregiver combined) with complete data were $€ 64,732$ (SE

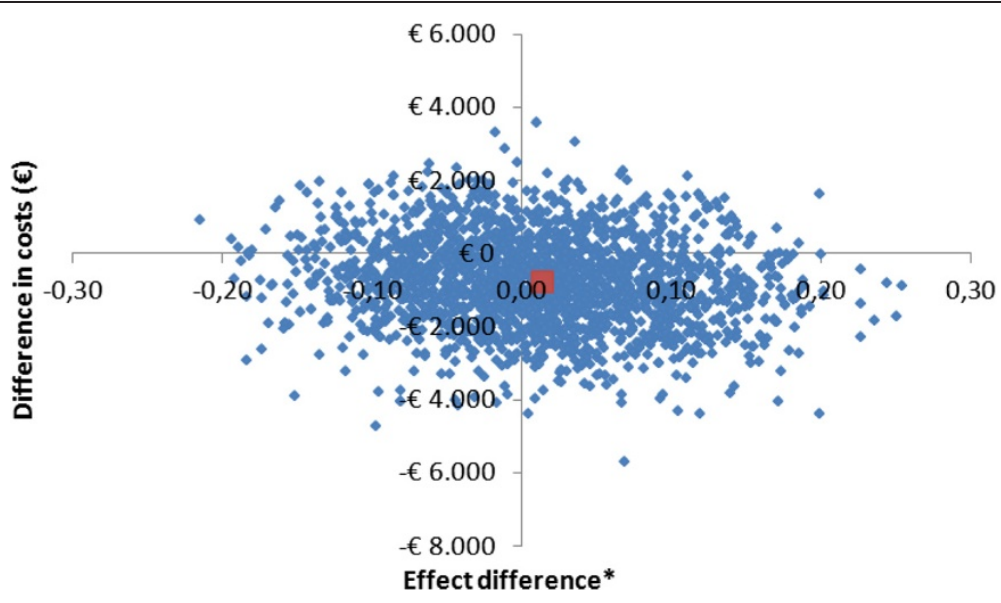

Figure 4 Cost-effectiveness plane for the incidence of depression and/or anxiety disorders in caregivers. *An effect difference $>0$ means that over a period of 12 months the risk of an incident depression and/or anxiety disorder was lower in the intervention group compared to the usual care group. 
$55,869)$ for the intervention group and $€ 63,303$ (SE 48,982) for the usual care group (mean adjusted cost difference $€ 3,951,95 \%$ CI $-17,662 ; 25,955)$. The second sensitivity analysis contained a repetition of the ITT analysis without adjustment for baseline imbalances between the intervention and control group. Also for this analysis the intervention was not considered cost-effective in comparison with usual care on any of the outcome measures and effect and cost differences for all outcomes remained non-significant (Table 4). Compared to the adjusted ITT analysis, only the MINI outcome reversed in favour of the usual care group, but this still involved a small and non-significant difference.

\section{Discussion}

\section{Main findings and interpretation}

This study is one of the first to investigate the impact of a dementia caregiver intervention from a societal perspective. Total annual costs were substantial and amounted to an average of $€ 77,832$ and $€ 75,201$ per care dyad (patient and caregiver combined) in the intervention and usual care group, respectively. These costs were much larger than expected based on previous estimates of dementia care costs $[9,46]$. Besides, almost half of the caregivers developed a mental disorder [32]. Moreover, this is the first study investigating whether a structured family meetings intervention for caregivers of persons with dementia is cost-effective in comparison with usual care. The most important cost drivers involved informal care costs and day treatment and admission costs of hospital and long-term care facility admissions of the patient. Over 12 months, we observed no significant differences in total costs between both groups. Based on the differences per cost category, our hypotheses that this intervention may decrease work absenteeism and healthcare utilization of the caregiver were not confirmed. Only ambulatory care costs differed amongst carers in the intervention and usual care group and were, unexpectedly, found to be increased amongst intervention carers. It could be possible that the intervention might have had an opposite effect by making caregivers realise they were stressed and therefore needing to seek help, increasing their use of ambulatory care. There were also no differences between groups in QALYs for both patients and caregivers or on clinical mental parameters for caregivers. Although, total costs for caregivers in the intervention group were somewhat lower than in the usual care group and effects were somewhat larger, cost-effectiveness planes showed that there was substantial uncertainty. Based on these findings, we conclude that family meetings are not cost-effective in comparison with usual care. A possible explanation for the non-significant findings was the minimal contrast between the intervention and control group as a consequence of the high level of standard care in the Netherlands. Future studies should focus on caregiving profiling based on who is most in need of family meetings support and who would benefit the most from this type of intervention. Besides, research should indicate to what extent or how it is possible to increase access, uptake and adherence.

\section{Comparison with the existing literature}

Our findings are in line with recent systematic reviews that demonstrated little evidence for the cost-effectiveness of non-pharmacological interventions for dementia patients and their informal caregivers [25,26]. Since this is the first cost-effectiveness study on family meetings, comparison of our results with similar studies is difficult. Overall, there is only little evidence on the cost-effectiveness of interventions supporting informal caregivers. From the systematic review of Jones et al. [25] only two randomized controlled trials can be identified that evaluated the cost-effectiveness of psychosocial interventions targeting informal caregivers of dementia patients that were performed from a societal perspective, which is considered as the most appropriate for economic evaluations [47]. The study by Graff et al. [27] found that community occupational therapy for dementia patients, including a training programme for caregivers in coping behaviours and supervision, was costeffective in comparison with usual care, and specifically reduced costs of informal caregiving [27]. Mean costs per patient involved $€ 12,563$ in the intervention group and $€ 14,311$ in the usual care group after 3 months of follow-up and were thus lower than in our study. Cost of caregivers' healthcare utilization and medication were not reported. The results of another economic evaluation by Wilson et al. [48] were in line with our findings. In this cost-utility study on a structured befriending service among 236 carers of people with a primary progressive dementia, the intervention was not found to be cost-effective [48]. Mean QALYs per carer over 15 months were only slightly higher (0.017) in the intervention group compared with the control groups and mean costs from a societal perspective were $£ 1,813$ higher. The randomized trial by Roberts et al. [49] that was included in the systematic review of Jones [25] evaluated the effects of an individualized problem-solving counselling intervention for caregivers and the expenditures of their health care utilization, but costs and effects were analysed separately [49]. Hence, this study cannot be considered a cost-effectiveness study.

Previously, the World Alzheimer Report [9] described that in high-income countries, the direct costs of social care (professional care in the community, and the costs of residential and nursing home care) amounted the most to the costs of dementia care (nearly 50\%) [9]. In our study, day treatment and admissions were also an important cost driver, but informal care costs accounted for the majority of the total costs (65\%). This is far higher than estimations in other cost of dementia studies. In the World Alzheimer Report [9], costs of informal care contributed $42 \%$ to total costs worldwide [9]. This 
can partly be explained by the fact that, in this report, informal care included only tasks associated with basic ADL and IADL, while in our study supervision time was also incorporated. In the present study, informal caregivers were mainly spouses living together with the person with dementia and part of them reported 'being on duty' 24 hours a day. Further, all patients in our sample were living in the community at baseline, while the World Alzheimer Report evaluation also consisted of people with dementia living in residential or nursing home care facilities. Other costing studies were more in line with our estimate and reported high informal care costs. Wilson et al. [48] found that costs of informal care contributed $85 \%$ to the total costs on a befriending program for carers of people with dementia [48]. In the study of Graff et al. [27] investigating occupational therapy for dementia patients [27], caregivers provided, on average, 11 hours a day which is similar with our findings. These numbers emphasize the importance of informal caregiving for people with dementia living in the community.

An interesting question is why so many of our sample developed a depressive or anxiety disorder. Caregivers were mainly women caring for their spouse with dementia. These groups of caregivers appear to be more vulnerable to experience adverse psychosocial and physical health effects $[3,50,51]$. Further, caregivers who experience high burden and have psychological complaints may have been more willing to participate in a trial testing a psychosocial intervention and therefore it is possible that recruited caregivers were at a higher risk of developing depression. On the other hand, the fact that they were willing to receive support may also have reduced their risk. The incidence in the present study is far higher than found in 'general' elderly cohorts [52-54] and is in line with the estimate of $48 \%$ reported in the review of Cuijpers et al. [3] on depressive disorders in caregivers of dementia patients [3]. This is an alarming finding and stresses the importance of further efforts to improve support for these caregivers. It is already known that caregiving for dementia patients is more stressful than caregiving for other older people, because of the specific demands that dementia poses on the caregiver such as being 'on duty' 24 hours a day and the fact that it often lasts much longer than other caregiving, which might explain the high vulnerability of this group $[8,55]$.

\section{Generalizability}

Although a substantial number of caregivers refused to participate in our study, patients and caregivers in our study did not differ significantly from the persons who declined participation with regard to gender, patient-caregiver relation and the service they were recruited from. Therefore, broadly, our sample seems to be representative for the population of caregivers and patients that receives care. The pragmatic character of this study, with few a priori exclusion criteria, resembling usual circumstances as much as possible greatly enhances the generalizability of our results to the population of caregivers and patients receiving care in daily practice.

\section{Strengths and limitations}

The major strength of this study is the detailed coverage of all relevant costs in this specific population, including detailed measurement of informal care. In this way, we were able to estimate the impact of the intervention from a societal perspective. The substantial contribution of informal care costs indicates the importance of including these costs when performing an economic evaluation in the field of dementia. Other strengths of this study involve the randomized design, the pragmatic approach that increases the applicability of the results to daily practice, and the relatively large sample size and long follow-up period. A limitation of the study is the rate of incomplete data. Complete follow-up data of costs and both the QALY and MINI effect outcomes were available for 101/192 (53\%) caregivers and 102/192 (53\%) patients. Data on costs were self-reported by the caregiver using cost diaries, which was rather time consuming for caregivers. Caregivers who considered withdrawal were offered a minimal assessment that included only the main effect parameters. This minimized dropout during the study, but decreased the completeness of cost data. On the other hand, the rate of incomplete data is partly due to the multi-factorial nature of data collection (especially on the resource use side), and is consistent with that seen in other studies. Poorer patients' health was significantly associated with having incomplete followup data, which could have influenced the results. However, to minimize the impact, we used multiple imputations to impute missing data. Previous studies have shown that simple procedures to handle missing data, like complete case analysis, can bias the cost estimates considerably and therefore multiple imputation is recommended to account for missing data [56,57]. In addition, results of the complete case analyses were in line with the main analyses, which strengthen the conclusion of this study that the intervention was not cost-effective in comparison with usual care.

\section{Conclusions}

This family meetings intervention for caregivers of persons with dementia was not cost-effective compared with usual care. Cost-effectiveness planes showed that there was considerable uncertainty. The limited contrast between the intervention and control group because of the high level of standard care in the Netherlands could have decreased the cost-effectiveness of the intervention. Future research should focus on factors that determine whether caregivers take up family meetings, and whether or how it is possible to increase the uptake and adherence, 
which might improve effectiveness and cost-effectiveness of the intervention. Although our study did not show any significant effects of family meetings or cost savings, the substantial number of caregivers who developed a mental disorder and the high informal care costs in both groups emphasize the need to search for interventions that support caregivers of dementia patients cost-effectively across the course of the illness.

\section{Abbreviations}

ADL: Activities of daily living; CEA: Cost-effectiveness acceptability; HDL: Household activities of daily living; IADL: Instrumental activities of daily living; ICER: Incremental cost-effectiveness ratio; ITT: Intention-to-treat; MINI: Mini International Neuropsychiatric Interview; QALY: Quality Adjusted Life-Years.

\section{Competing interests}

Funding from this study was obtained from the Netherlands Organization for Health Research and Development (ZonMw), grant number 62300040. The funders had no role in study design, data collection and analysis, decision to publish, or preparation of the manuscript. The authors declare that they have no competing interests.

\section{Authors' contributions}

$\mathrm{KJ}$ managed the trial, performed the statistical analysis and drafted the manuscript. JB assisted with the data analysis and helped to draft the manuscript. HPH acted as principal investigator. $\mathrm{K}, \mathrm{HPH}, \mathrm{HM}, \mathrm{HEH}, \mathrm{PS}$ and JB participated in the design of the study. JMV checked the cleaning and transformation of the data. All authors contributed to writing the manuscript, read and approved the final manuscript.

\section{Author details}

'Department of General Practice and Elderly Care Medicine, VU University Medical Centre, EMGO + Institute for Health and Health Care Research, Van der Boechorststraat 7, 1081, BT Amsterdam, The Netherlands. ${ }^{2}$ Faculty of Earth and Life Sciences, VU University Amsterdam, De Boelelaan 1085, 1081, HV Amsterdam, The Netherlands. ${ }^{3}$ Department of Neurology, VUmc Alzheimer Center, De Boelelaan 1118, 1081, HZ Amsterdam, The Netherlands. ${ }^{4}$ Department of Internal Medicine, Section Geriatrics, Amsterdam Medical Center, Meibergdreef 9, 1105, AZ Amsterdam, The Netherlands.

Received: 12 April 2013 Accepted: 11 September 2013 Published: 22 September 2013

\section{References}

1. World Health Organization: Alzheimer's Disease International. Dementia. A Public Health Priority. Geneva: WHO; 2012.

2. Aneshensel CS, Pearlin LI, Mullan JT, Zarit SH, Whitlatch CJ: Profiles in Caregiving: The Unexpected Career. New York: Academic Press; 1995.

3. Cuijpers P: Depressive disorders in caregivers of dementia patients: a systematic review. Aging Ment Health 2005, 9:325-330.

4. Neundorfer MM, McClendon MJ, Smyth KA, Strauss ME, McCallum TJ: Does depression prior to caregiving increase vulnerability to depressive symptoms among caregivers of persons with Alzheimer's disease? Aging Ment Health 2006, 10:606-615.

5. Schulz R, O'Brien AT, Bookwala J, Fleissner K: Psychiatric and physical morbidity effects of dementia caregiving: prevalence, correlates, and causes. Gerontologist 1995, 35:771-791.

6. Vitaliano PP, Zhang J, Scanlan JM: Is caregiving hazardous to one's physical health? A meta-analysis. Psychol Bull 2003, 129:946-972.

7. Whitlatch CJ, Feinberg LF, Sebesta DS: Depression and health in family caregivers: adaptation over time. J Aging Health 1997, 9(2):222-243.

8. Ory MG, Hoffman RR, Yee JL, Tennstedt S, Schulz R: Prevalence and impact of caregiving: a detailed comparison between dementia and nondementia caregivers. Gerontologist 1999, 39:177-185.

9. Alzheimer's Disease International: World Alzheimer Report 2010. The Global Economic Impact of Dementia. London: Alzheimer's Disease International; 2010.
10. Meerding WJ, Bonneux L, Polder JJ, Koopmanschap MA, van der Maas PJ: Demographic and epidemiological determinants of healthcare costs in Netherlands: cost of illness study. BMJ 1998, 317:111-115.

11. Wimo A, Jönsson B, Karlsson G, Winblad B: Health economics approaches to dementia. In The Health Economics of Dementia. Chichester: John Wiley; 1998.

12. Wimo A, Winblad B, Aguero-Torres H, von Strauss E: The magnitude of dementia occurrence in the world. Alzheimer Dis Assoc Disord 2003, 17:63-67.

13. Alzheimer's Association, Thies W, Bleiler L: Alzheimer's disease facts and figures. Alzheimer's Dement 2011, 7:208-244.

14. Jonsson L, Eriksdotter JM, Kilander L, Soininen $H$, Hallikainen M, Waldemar G, Nygaard H, Andreasen N, Winblad B, Wimo A: Determinants of costs of care for patients with Alzheimer's disease. Int I Geriatr Psychiatry 2006, 21:449-459.

15. Luengo-Fernandez R, Leal J, Gray A: Dementia 2010. The Economic Burden of Dementia and Associated Research Finding in the United Kingdom. Cambridge: Alzheimer's Research Trust; 2010.

16. Buchan J: The 'greying' of the United Kingdom nursing workforce: implications for employment policy and practice. J Adv Nurs 1999, 30:818-826.

17. General Accounting Office: Nursing workforce: Emerging Nurse Shortage due to Multiple Factors. Washington, DC: GAO; 2001.

18. Health Council of the Netherlands: Dementia. Publication no. 2002/04. The Hague: Health Council of the Netherlands; 2002.

19. Institute of Medicine: Retooling for an Aging America: Building the Health Care Workforce. Washington DC: National Academies Press; 2008.

20. Mittelman MS, Ferris SH, Shulman E, Steinberg G, Levin B: A family intervention to delay nursing home placement of patients with Alzheimer disease. A randomized controlled trial. JAMA 1996, 276:1725-1731.

21. Mittelman MS, Haley WE, Clay OJ, Roth DL: Improving caregiver well-being delays nursing home placement of patients with Alzheimer disease. Neurology 2006, 67:1592-1599.

22. Brodaty H, Green A, Koschera A: Meta-analysis of psychosocial interventions for caregivers of people with dementia. J Am Geriatr Soc 2003, 51:657-664.

23. Olazaran J, Reisberg B, Clare L, Cruz I, Pena-Casanova J, Del Ser T, Woods B, Beck C, Auer S, Lai C, Spector A, Fazio S, Bond J, Kivipelto M, Brodaty H, Rojo JM, Collins H, Teri L, Mittelman M, Orrell M, Feldman HH, Muñiz R: Nonpharmacological therapies in Alzheimer's disease: a systematic review of efficacy. Dement Geriatr Cogn Disord 2010, 30:161-178.

24. Sorensen $S$, Pinquart $M$, Duberstein $P$ : How effective are interventions with caregivers? An updated meta-analysis. Gerontologist 2002, 42:356-372.

25. Jones C, Edwards RT, Hounsome B: A systematic review of the costeffectiveness of interventions for supporting informal caregivers of people with dementia residing in the community. Int Psychogeriatr 2012, 24:6-18.

26. Knapp M, lemmi V, Romeo R: Dementia care costs and outcomes: a systematic review. Int J Geriatr Psychiatry 2013, 28(6):551-561.

27. Graff MJ, Adang EM, Vernooij-Dassen MJ, Dekker J, Jonsson L, Thijssen M, Hoefnagels WH, Rikkert MG: Community occupational therapy for older patients with dementia and their care givers: cost effectiveness study. BMJ 2008, 336:134-138.

28. Mittelman MS, Ferris SH, Shulman E, Steinberg G, Ambinder A, Mackell JA, Cohen J: A comprehensive support program: effect on depression in spouse-caregivers of AD patients. Gerontologist 1995, 35:792-802.

29. Mittelman MS, Roth DL, Coon DW, Haley WE: Sustained benefit of supportive intervention for depressive symptoms in caregivers of patients with Alzheimer's disease. Am J Psychiatry 2004, 161:850-856.

30. Mittelman MS, Ferris SH, Steinberg G, Shulman E, Mackell JA, Ambinder A, Cohen J: An intervention that delays institutionalization of Alzheimer's disease patients: treatment of spouse-caregivers. Gerontologist 1993, 33:730-740.

31. Joling K, Van Hout HP, Scheltens P, Vernooij-Dassen M, van den Berg B, Bosmans J, Gillissen F, Mittelman M, van Marwijk HW: (Cost)-effectiveness of family meetings on indicated prevention of anxiety and depressive symptoms and disorders of primary family caregivers of patients with dementia: design of a randomized controlled trial. BMC Geriatr 2008, 8:2.

32. Joling KJ, van Marwijk HW, Smit F, van der Horst HE, Scheltens $P$, van de Ven P, Mittelman MS, van Hout HPJ: Does a family meetings intervention prevent depression and anxiety in family caregivers of dementia patients? A randomized trial. PLoS One 2012, 7:e30936.

33. Joling KJ, van Marwijk HW, van der Horst HE, Scheltens P, van de Ven PM, Appels BA, van Hout HPJ: Effectiveness of family meetings for family 
caregivers on delaying time to nursing home placement of dementia patients: a randomized trial. PLOS One 2012, 7:e42145.

34. Sheehan DV, Lecrubier $Y$, Sheehan KH, Amorim P, Janavs J, Weiller $E$ Hergueta T, Baker R, Dunbar GC: The Mini-International Neuropsychiatric Interview (M.I.N.I.): the development and validation of a structured diagnostic psychiatric interview for DSM-IV and ICD-10. J Clin Psychiatry 1998, 59(Suppl 20):22-33.

35. Ware JE, Kosinski M, Keller S: A 12-item short form Health Survey: construction of scales and preliminary tests of reliability and validity. Med Care 1996, 34:220-233.

36. Brazier JE, Roberts J: The estimation of a preference-based measure of health from the SF-12. Med Care 2004, 42:851-859.

37. Hakkaart-van Roijen L, Tan SS, Bouwmans CAM: Handleiding voor kostenonderzoek: Methoden en standaard kostprijzen voor economische evaluaties in de gezondheidszorg. Geactualiseerde versie 2010. [Dutch manual for costing in economic evaluations]. Diemen: College voor zorgverzekeringen (CVZ); 2011.

38. Z-index: Z-index: G-Standaard. The Netherlands: The Hague, College voor Zorgverzekeringen (CVZ); 2006

39. Koopmanschap MA, Rutten FF, van Ineveld BM, van Roijen L: The friction cost method for measuring indirect costs of disease. J Health Econ 1995 14:171-189.

40. Oostenbrink JB, Bouwmans CAM, Koopmanschap MA, Rutten FF: Handleiding voor kostenonderzoek: Methoden en standaard kostprijzen voor economische evaluaties in de gezondheidszorg, Geactualiseerde versie 2004 edn. College voor. Diemen: Zorgverzekeringen; 2004.

41. Rubin DB: Multiple Imputation for Nonresponse in Surveys. New York: John Wiley \& Sons; 1987.

42. Zigmond AS, Snaith RP: The hospital anxiety and depression scale. Acta Psychiatr Scand 1983, 67:361-370.

43. Burton A, Billingham $\sqcup$, Bryan S: Cost-effectiveness in clinical trials: using multiple imputation to deal with incomplete cost data. Clin Trials 2007, 4:154-161.

44. Efron B: Missing data, imputation and the bootstrap. J Am Stat Assoc 1994, 89:463-475.

45. Fenwick $E, O^{\prime} B r i e n ~ B J$, Briggs $A$ : Cost-effectiveness acceptability curvesfacts, fallacies and frequently asked questions. Health Econ 2004, 13:405-415.

46. Wimo A, Winblad B, Jonsson L: An estimate of the total worldwide societal costs of dementia in 2005. Alzheimers Dement 2007, 3:81-91.

47. Byford S, Raftery J: Perspectives in economic evaluation. BMJ 1998, 316:1529-1530.

48. Wilson E, Thalanany M, Shepstone L, Charlesworth G, Poland F, Harvey I, Price D, Reynolds S, Mugford M: Befriending carers of people with dementia: a cost utility analysis. Int J Geriatr Psychiatry 2009, 24:610-623.

49. Roberts J, Browne G, Milne C, Spooner L, Gafni A, Drummond-Young M, LeGris J, Watt S, LeClair K, Beaumont L, Roberts J: Problem-solving counseling for caregivers of the cognitively impaired: effective for whom? Nurs Res 1999, 48:162-172.

50. Pinquart $M$, Sorensen $S$ : Gender differences in self-concept and psychological well-being in old age: a meta-analysis. J Gerontol B Psychol Sci Soc Sci 2001, 56:195-213.

51. Schulz R, Williamson GM: A 2-year longitudinal study of depression among Alzheimer's caregivers. Psychol Aging 1991, 6:569-578.

52. Luijendijk HJ, van den Berg JF, Dekker MJ, van Tuijl HR, Otte W, Smit F, Hofman A, Stricker BH, Tiemeier H: Incidence and recurrence of late-life depression. Arch Gen Psychiatry 2008, 65:1394-1401.

53. Norton MC, Skoog I, Toone L, Corcoran C, Tschanz JT, Lisota RD, Hart AD, Zandi PP, Breitner JC, Welsh-Bohmer KA, Steffens DC, Cache County Investigators: Three-year incidence of first-onset depressive syndrome in a population sample of older adults: the Cache County study. Am J Geriatr Psychiatry 2006, 14:237-245.

54. Palsson SP, Ostling S, Skoog I: The incidence of first-onset depression in a population followed from the age of 70 to 85 . Psychol Med 2001, 31:1159-1168.
55. Alzheimer's Association: Alzheimer's Disease. Facts and Figures. Alzheimer's \& Dementia, volume 6. Alzheimer's Association: Washington, DC; 2010.

56. Oostenbrink JB, Al MJ: The analysis of incomplete cost data due to dropout. Health Econ 2005, 14:763-776.

57. Briggs A, Clark T, Wolstenholme J, Clarke P: Missing... presumed at random: cost-analysis of incomplete data. Health Econ 2003, 12:377-392.

doi:10.1186/1745-6215-14-305

Cite this article as: Joling et al:: The cost-effectiveness of a family meetings intervention to prevent depression and anxiety in family caregivers of patients with dementia: a randomized trial. Trials $201314: 305$

\section{Submit your next manuscript to BioMed Central and take full advantage of:}

- Convenient online submission

- Thorough peer review

- No space constraints or color figure charges

- Immediate publication on acceptance

- Inclusion in PubMed, CAS, Scopus and Google Scholar

- Research which is freely available for redistribution 